\title{
Frontières
}

\section{Récit en abyme}

Après le 11 septembre...

\section{Michèle Emond}

Volume 14, numéro 1, automne 2001

Où est la marge ?

URI : https://id.erudit.org/iderudit/1074165ar

DOI : https://doi.org/10.7202/1074165ar

Aller au sommaire du numéro

Éditeur(s)

Université du Québec à Montréal

ISSN

1180-3479 (imprimé)

1916-0976 (numérique)

Découvrir la revue

Citer ce document

Emond, M. (2001). Récit en abyme : après le 11 septembre... Frontières, 14(1),

67-67. https://doi.org/10.7202/1074165ar

Ce document est protégé par la loi sur le droit d'auteur. L'utilisation des services d'Érudit (y compris la reproduction) est assujettie à sa politique d'utilisation que vous pouvez consulter en ligne.

https://apropos.erudit.org/fr/usagers/politique-dutilisation/
Cet article est diffusé et préservé par Érudit.

Érudit est un consortium interuniversitaire sans but lucratif composé de l’Université de Montréal, l’Université Laval et l'Université du Québec à Montréal. Il a pour mission la promotion et la valorisation de la recherche. https://www.erudit.org/fr/ 


\section{RÉCIT EN ABYME Après le 11 septembre...}

\author{
Michèle Emond, \\ professeure, Département de sociologie, \\ Collège Édouard-Montpetit.
}

Une table ronde réunissait Jean-François Lépine, Madeleine Gagnon, Wajdi Mouawad et Michel Giguère lors d'une Soirée JulienBigras à la Bibliothèque nationale, le 26 octobre dernier.

Il y avait foule. Une salle aux murs anciens, un peu comme si l'Institut canadien revivait et que la Société psychanalytique de Montréal, organisatrice de la soirée avait trouvé un lieu de libre parole. Assistance composée de psychanalystes, surtout des femmes, d'étudiantes, de couples psys ou enseignants. Pourrais-je décrire cette soirée comme une communion, quand des êtres d'esprit et de chair essaient de se dire, sans mentir? Choisir des écrivains, un journaliste, des psychanalystes, habitués au pathos, à la transfiguration des émotions par les mots, n'était-ce pas une façon de réfléchir au chaos de la douleur à partir d'un lieu, celui de la réserve et de la bonne distance?

Jean-François Lépine se présente comme un descripteur de la douleur rencontrée en Éthiopie, Rwanda, Palestine, pays en guerre mais aussi Inde, pays de résistance séculaire à la misère. En l'écoutant, je cherchais sa force, celle qui lui permettait de croiser le chemin de mourants. Lui-même ne la connaît pas et avoue qu'il devient un peu insensible. Conscient de la banalisation de la souffrance à distance qu'opèrent les médias, il semble englué dans son rôle, d'où sa fascination pour ses manifestations agonistiques: une mère qui perd son fils, un jeune Iranien servant d'éclaireur et de détonateur dans les champs de mine.

Madeleine Gagnon parle en détachant les mots, avec un reste d'enfance. Femme d'engagement, elle distingue douleur, qui est ressentie, de souffrance, qui cherche à inter- préter le chaos innommable. À qui dire l'intime de la douleur? Pourquoi ? Sinon pour chercher chez l'autre l'apaisement, la fin du tourment? Les musulmanes, prisonnières dans leur corps, se sont confiées avec l'idée que les femmes d'ici, au-delà des voiles, éprouveraient la douleur de l'oppression commune. Et puis ces jeunes martyrs, prêts à nourrir l'autel des sacrifices à chaque carrefour israélien, comment les mères peuvent-elles les pleurer? Elle dira aussi comment elle a survécu à un curetage sans anesthésie aux mains d'un médecin étranger... à la souffrance.

Wajdi Mouawad, l'homme de théâtre joue l'authenticité. Il avoue qu'il se sent analysé par la salle et préférerait que l'inconscient le reste. Tiens, un Woody Allen libanais! Élevé dans la haine des Israéliens, puis des Syriens, il ne s'étonne pas que plusieurs camarades soient devenus membres des milices chrétiennes. Il vit la guerre dans une famille convenable où la dignité étouffe. Exilés en France, ses proches se réfugient dans la nostalgie d'un retour au pays. Au Québec par la suite, il n'éprouvera nulle douleur lors de la mort de sa mère et n'exprimera sa colère que dans la mise en spectacle, bien latine, bien contrôlée. Il lira un texte, où un jeune tueur fou donne la mort, en série, crachant sa haine, reniant ses pères et mères, ceux qui ont nourri cette violence. Tak kat ak kata! Dans cet univers, il ne reste que les mots des armes. Mort, silence, désarroi.

Après ce rappel que la douleur est d'abord chaos, la voix de Michel Giguère, un peu éteinte, comme en écho, plonge dans l'atmosphère de la séance. Il raconte une histoire, celle que la clinique nommera Douleur et Souffrance, sa jumelle. Pourquoi suis-je tombée en abîme en écoutant le récit de ce cas, à la fois différent et intime? Pudeur, retour sur soi, les mots ne m'atteignaient pas. Comme ma souffrance, qui me protège de la douleur, que je refuse de nommer mienne. Rappel d'un moment où je me sens déportée, sous son emprise. Puis le récit reprend ma main et j'entends qu'au-delà du transfert, l'analyse propose l'accompagnement vers une vie neuve.

Lors de la période d'échanges, Dan Bigras, venu à cause de son père, fera son show pour le Refuge, au nom de tous ses frères, morts de la douleur d'une famille souffrante. Il dira aussi que les psys, faut s'en méfier, car ils font des mots pour refuser la douleur. À cette voix, il oppose le cri paroxystique, le refus d'endurer qui se nomme révolte ou suicide. Il rappelle que la souffrance des jeunes de la rue reste la moins prise en compte par la pratique quotidienne des psychanalystes.

Les invités ont donc abordé la douleur par sa dimension la plus politique, celle des massacres et des oppressions qui se nourrissent de la haine de l'autre, son mépris, faisant de tous des victimes et des agresseurs, identifiables ou anonymes. Qu'en estil des autres douleurs, celles plus banales dont meurent la majorité des individus de nos sociétés: la longue maladie, l'usure de la pompe à sang ou les chocs du fracas automobile? Et puis, celles qu'on s'inflige dans la toxicomanie ou dans la recherche de sens au travail ? Ou celles qui consument à petit feu: le rejet, la honte d'avoir été agressée, la perte de la dignité.

Une dernière intervention, celle d'une psy, rappelait qu'en faisant des porteurs de violence des êtres fanatisés et jouissifs de leur souffrance, des martyrs, on cherchait peut-être à éloigner le calice de nos lèvres et par là, on trouve des ennemis à haïr à bon compte. Talibans, Musulmans, Israéliens, Américains, autant d'hommes en souffrance. Dans le contexte d'après le 11 septembre, la remarque mérite réflexion. 